- News \& Views •

\title{
Atmospheric Profiling Synthetic Observation System in Tibet
}

\author{
Daren $\mathrm{LU}^{1,2}$, Weilin PAN ${ }^{* 1,2}$, and Yinan $\mathrm{WANG}^{1}$ \\ ${ }^{1}$ Institute of Atmospheric Physics, Chinese Academy of Sciences, Beijing 100029, China \\ ${ }^{2}$ University of Chinese Academy of Sciences, Beijing 100049, China
}

(Received 16 October 2017; revised 20 November 2017; accepted 24 November 2017)

Citation: Lu, D. R., W. L. Pan, and Y. N. Wang, 2018: Atmospheric Profiling Synthetic Observation System in Tibet. Adv. Atmos. Sci., 35(3), 264-267, https://doi.org/10.1007/s00376-017-7251-7.

\section{Introduction}

The Atmosphere Profiling Synthetic Observation System (APSOS) is the first ground-based facility for profiling atmospheric variables and multiple constituents in the whole (neutral) atmosphere from the surface up to the lower thermosphere. It enables simultaneous observations and extensive studies of the atmospheric vertical structure and constituent transport.

The program under which this new facility was developed, funded by the National Natural Science Foundation of China, was launched in 2012 for developing a cluster of state-of-the-art instruments to facilitate atmospheric studies over the Tibetan Plateau (TP). After a one-year test run in Anhui Province at the Huainan Division of the Institute of Atmospheric Physics (IAP), Chinese Academy of Sciences
(CAS) $\left(32.62^{\circ} \mathrm{N}, 116.98^{\circ} \mathrm{E}\right)$, APSOS was recently deployed at its final destination-Yangbajain (YBJ) International Cosmic Ray Observatory $\left(30.21^{\circ} \mathrm{N}, 90.43^{\circ} \mathrm{E}\right.$; $\left.4300 \mathrm{~m} \mathrm{MSL}\right)$, located in YBJ valley, about $90 \mathrm{~km}$ northwest of the city of Lhasa, the Tibet Autonomous Region, China. Figure 1 shows an aerial view of the newly established observatory for APSOS in YBJ.

\section{Scientific motivation}

The TP, often referred as the Third Pole, along with the Arctic and Antarctica, are the three most sensitive regions of the Earth's atmosphere (Holland and Bitz, 2003; Du et al., 2004). It covers an area of about 2.5 million $\mathrm{km}^{2}$, with its surface in the middle troposphere, acting like a giant heat-

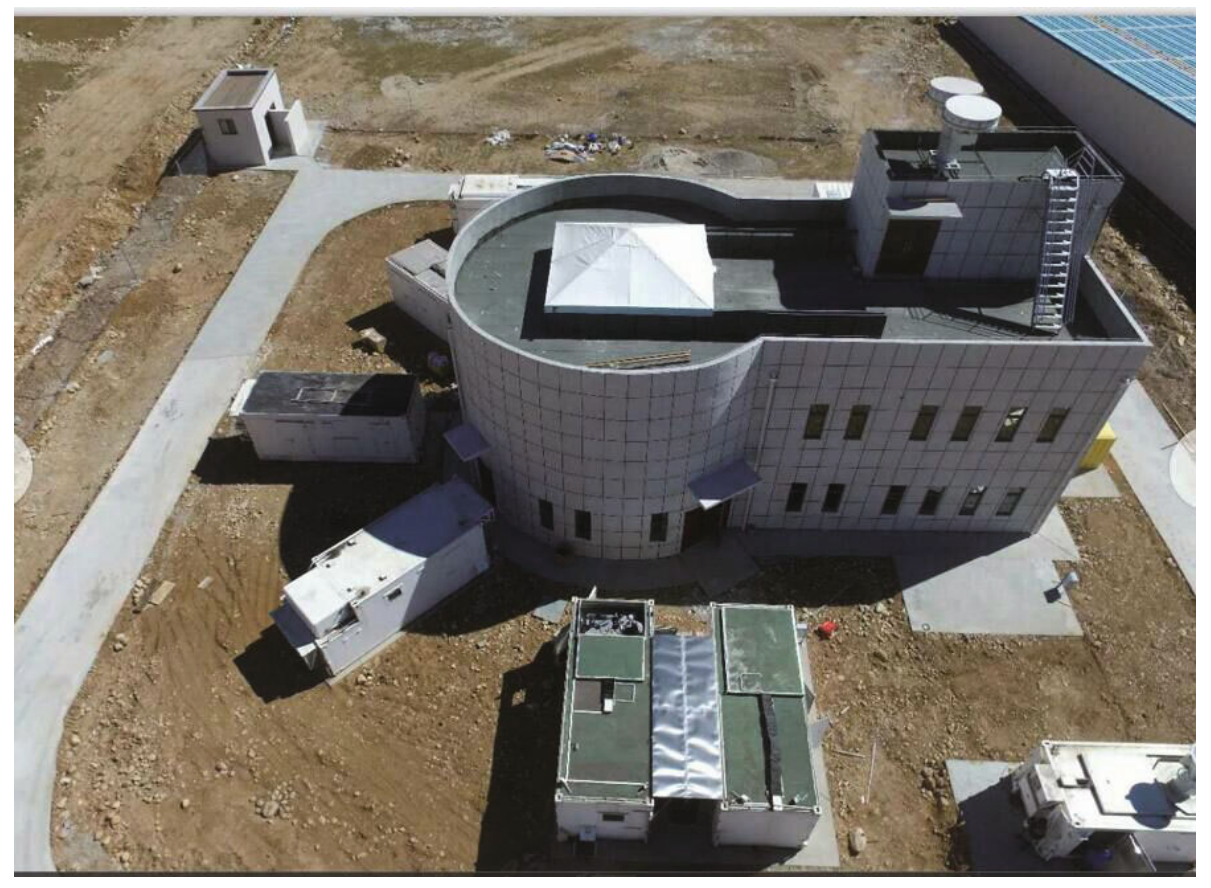

Fig. 1. Aerial view of APSOS at YBJ.

\footnotetext{
* Corresponding author: Weilin PAN

Email: panweilin@mail.iap.ac.cn
} 
ing "plate". This heating mechanism not only pumps the air upwards to influence the atmospheric circulation, but also intensifies monsoons by setting up a pressure gradient between the land and sea. (Molnar et al., 1993; Wang et al., 2008; Boos and Kuang, 2010).

For decades, satellites and radiosondes have been monitoring the atmosphere over the TP. Satellite data have revealed a low center of total column ozone over the TP in summer and confirmed that the TP is a pathway of mass exchange between the troposphere and stratosphere (Zhou et al., 2006). Models and satellite observations show that monsoon circulation provides an effective pathway over the TP for water vapor and pollution to enter the global stratospheric circulation (Fu et al., 2006; Park et al., 2009; Randel et al., 2010; Yu et al., 2017). However, strong demands still exist in the TP region for ground-based atmospheric observations with high vertical and temporal resolutions.

By providing range-resolved atmospheric measurements from the troposphere, stratosphere, mesosphere, and up to the lower thermosphere in the TP region, the aim of APSOS is to investigate neutral atmospheric dynamics, physical and chemical processes, and the coupling between layers; to study the compositional changes and constituent transport in the vertical direction; to characterize greenhouse effects, such as warming in the lower atmosphere and cooling in the upper atmosphere (Ramaswamy et al., 2001); to provide groundbased measurements for satellite data calibration and validation; and to study the atmospheric response to solar activities, as well as natural and anthropogenic influences.

\section{Key instruments}

Based on a unique combination of the most advanced active and passive remote sensing techniques, APSOS is operated at multiple wavelengths, ranging from ultraviolet to infrared, and from terahertz to millimeters. It consists of several state-of-the-art instruments, for measuring rangeresolved parameters of the whole (neutral) atmosphere, from the surface up to $110 \mathrm{~km}$, covering the altitude of the troposphere, stratosphere, mesosphere, and lower thermosphere. The measurements can achieve vertical resolution on the order of tens of meters, and temporal resolution on the order of minutes.

The system mainly consists of five lidars (devoted to observing the vertical structure of atmospheric temperature, wind, water vapor, ozone, $\mathrm{CO}_{2}, \mathrm{SO}_{2}, \mathrm{NO}_{2}$, aerosol, cloud, and the sodium layer), a W-band dual polarization cloud radar, a superconducting terahertz radiometer, and an integrated telescope. Shown in Fig. 2 are the measurement capabilities of APSOS from the surface up to the lower thermosphere.

The key instruments of APSOS include:

(1) Aerosol-cloud- $\mathrm{H}_{2} \mathrm{O}$ Mie/Raman lidar-for monitoring the vertical distributions of water vapor, aerosol, and cloud. Figure 3 shows the first APSOS "light" (laser beam)

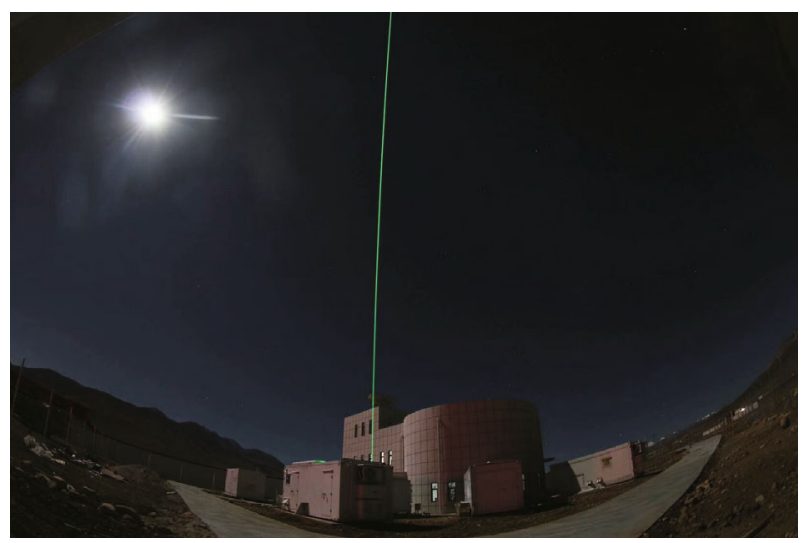

Fig. 3. The laser beam of the Aerosol-cloud- $\mathrm{H}_{2} \mathrm{O}$ Mie/Raman lidar.

\section{Capabilities of APSOS}

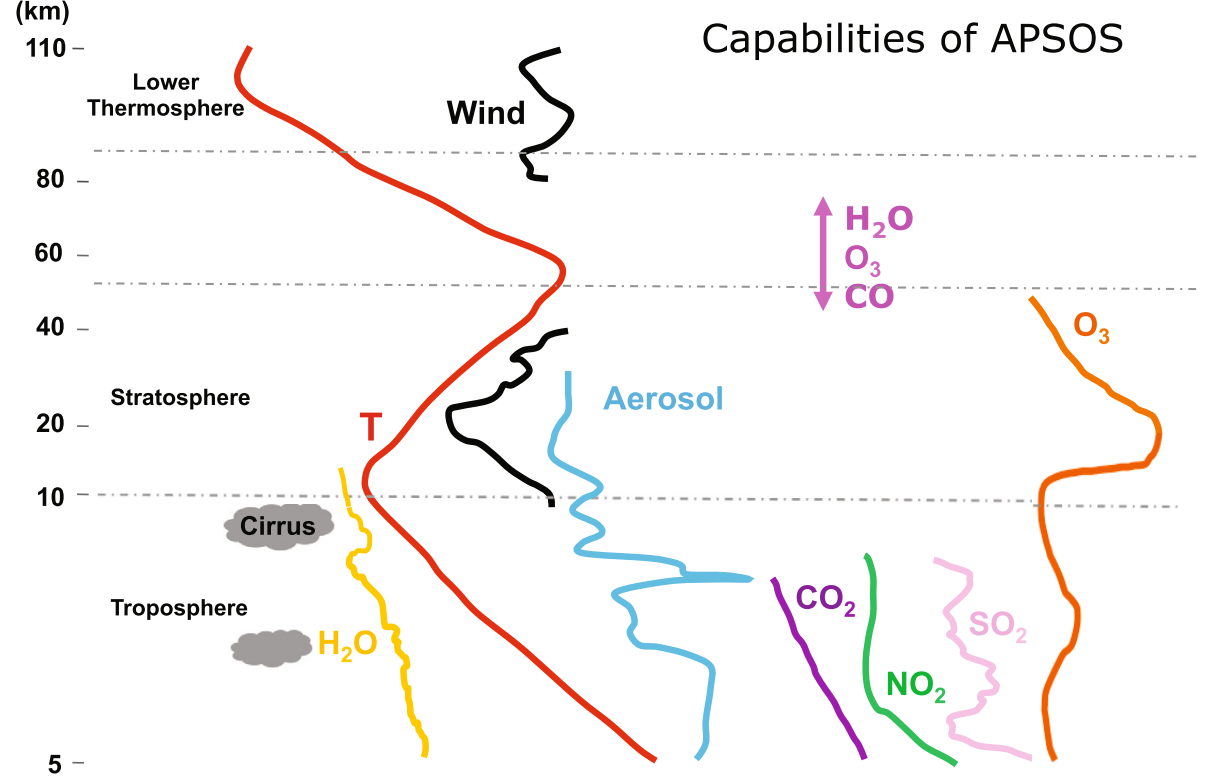

Fig. 2. Measurement capabilities of APSOS in the whole (neutral) atmosphere. 


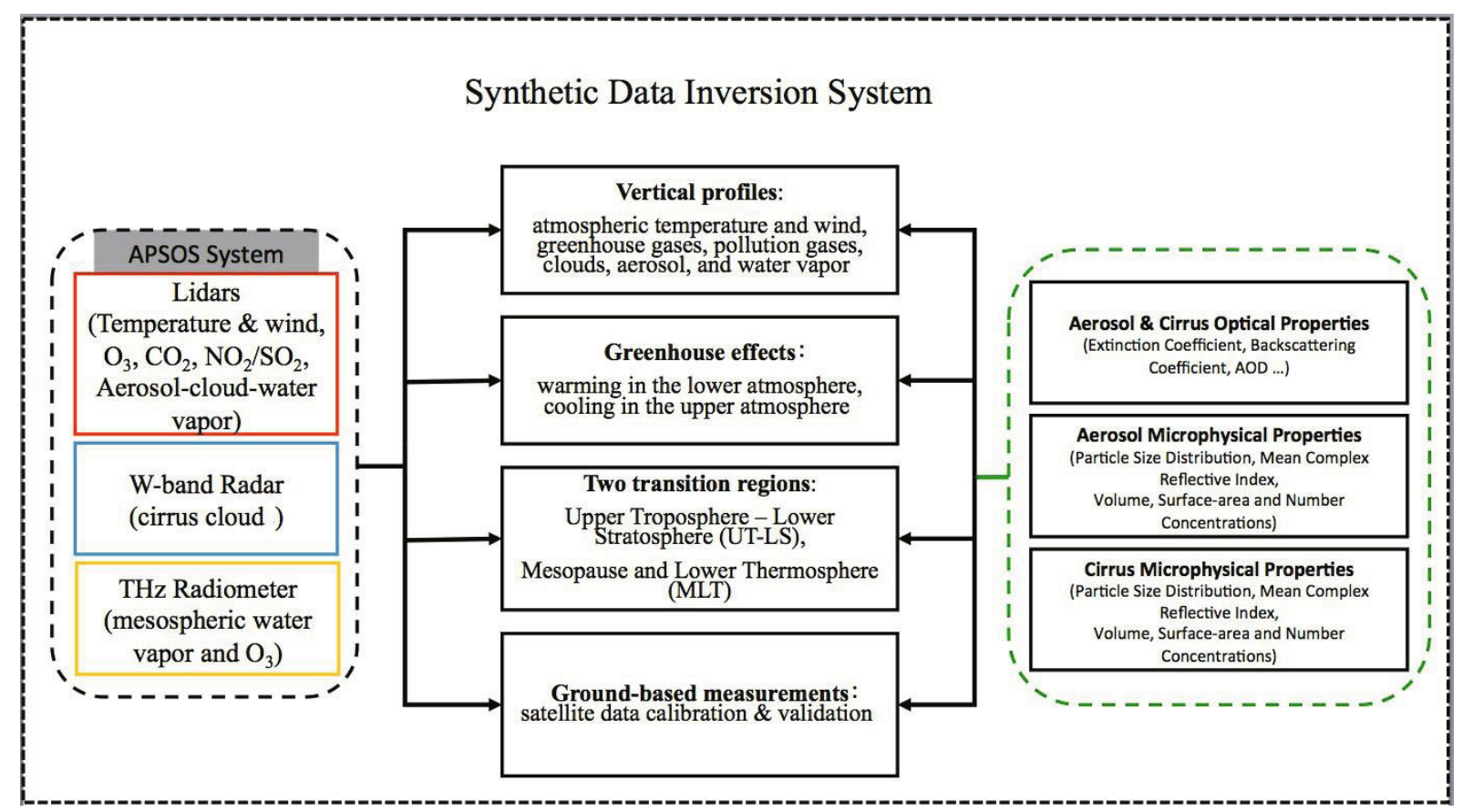

Fig. 4. APSOS data retrieval scheme.

being transmitted up into the night sky on 4 October 2017 at YBJ.

(2) $\mathrm{Na} /$ Rayleigh/Raman temperature and wind lidar-for measuring the range-resolved profiles of temperature (5-110 $\mathrm{km})$ and wind (10-40 km, 80-110 km).

(3) Multiple DIAL (differential absorption lidar)—for measuring the range-resolved concentration profiles of ozone (5-50 km), $\mathrm{CO}_{2}$ and $\mathrm{NO}_{2} / \mathrm{SO}_{2}$ from the surface to the height of $3 \mathrm{~km}$.

(4) Integrated telescope - an optical assembly made by four $\Phi 1200 \mathrm{~mm}$ mirrors, yielding an equivalent lidar receiver aperture of $\sim 2 \mathrm{~m}$.

(5) W-band radar-for measuring the distribution and phase of non-precipitating cloud (including cirrus).

(6) Terahertz radiometer-capable of "seeing through" cloud, for measuring mesospheric ozone and water vapor.

In addition to the instruments listed above, there is a data management and validation platform for APSOS data retrieval, and for comparison with radiosonde, ozonesonde, stratospheric balloon, and satellite measurements. Figure 4 is an example of APSOS data inversion architecture. The measured optical properties of aerosol by multi-wavelength Mie and Raman scattering lidars in terms of backscatter and extinction can be processed to attain the microphysical properties. By combining the optical and microphysical properties observed by lidars and cloud radar, the system can provide more information on cloud-aerosol interactions.

\section{Future plans}

APSOS was developed by IAP, CAS, in collaboration with the Wuhan Institute of Physics and Mathematics/CAS, the University of Science and Technology of China, the Anhui Institute of Optics and Fine Mechanics/CAS, the Purple Mountain Observatory/CAS, Wuhan University, and Anhui Sun Create Electronics.

The current version of APSOS will be in full operation by the end of 2017. Two more instruments will be added in 2018, including a Ka-band cloud radar and an atmospheric emitted radiance interferometer.

In the next decade, APSOS will be making long-term measurements and establishing the first whole-atmosphere database over the TP. It will help to explore the interactions between the troposphere and stratosphere and to explain the phenomena of summertime ozone depletion in this area. Consequently, it has the potential to deepen our understanding of the physicochemical processes and the layered coupling mechanism in the whole atmosphere. International collaborations from related science communities are strongly encouraged.

Acknowledgements. This work is supported by the National Natural Science Foundation of China (Grant No. 41127901). The authors would like to acknowledge all APSOS team members for their tremendous efforts in system development and for overcoming high-altitude difficulties at YBJ. We are also thankful to the Institute of High Energy Physics, CAS, for providing the observation site.

\section{REFERENCES}

Boos, W. R., and Z. M. Kuang, 2010: Dominant control of the South Asian monsoon by orographic insulation versus plateau heating. Nature, 463(7278), 218-222, http://dx.doi. org/10.1038/nature08707.

Du, M. Y., S. Kawashima, S. Yonemura, X. Z. Zhang, and S. 
B. Chen, 2004: Mutual influence between human activities and climate change in the Tibetan Plateau during recent years. Global E Planetary Change, 41(3-4), 241-249, http://dx.doi.org/10.1016/j.gloplacha.2004.01.010.

Fu, R., and Coauthors, 2006: Short circuit of water vapor and polluted air to the global stratosphere by convective transport over the Tibetan Plateau. Proceedings of the National Academy of Sciences of the United States of America, 103, 5664-5669, http://dx.doi.org/10.1073/pnas.0601584103.

Holland, M. M., and C. M. Bitz, 2003: Polar amplification of climate change in coupled models. Climate Dyn., 21(3-4), 221232, http://dx.doi.org/10.1007/s00382-003-0332-6.

Molnar, P., P. England, and J. Martinod, 1993: Mantle dynamics, uplift of the Tibetan Plateau, and the Indian monsoon. Rev. Geophys., 31(4), 357-396, http://dx.doi.org/10.1029/ 93RG02030.

Park, M., W. J. Randel, L. K. Emmons, and N. J. Livesey, 2009: Transport pathways of carbon monoxide in the Asian summer monsoon diagnosed from Model of Ozone and Related Tracers (MOZART). J. Geophys. Res., 114, D08303,
http://dx.doi.org/doi:10.1029/2008JD010621.

Ramaswamy, V., and Coauthors, 2001: Stratospheric temperature trends: Observations and model simulations. Rev. Geophys., 39(1), 71-122, http://dx.doi.org/10.1029/1999RG000065.

Randel, W. J., M. Park, L. Emmons, D. Kinnison, P. Bernath, K. A. Walker, C. Boone, and H. Pumphrey, 2010: Asian monsoon transport of pollution to the stratosphere. Science, 328, 611-613, http://dx.doi.org/10.1126/science. 1182274.

Wang, B., Q. Bao, B. Hoskins, G. X. Wu, and Y. M. Liu, 2008: Tibetan Plateau warming and precipitation changes in East Asia. Geophys. Res. Lett., 35, L14702, http://dx.doi.org/doi: 10. 1029/2008GL034330.

Yu, P. F., and Coauthors, 2017: Efficient transport of tropospheric aerosol into the stratosphere via the Asian summer monsoon anticyclone. Proceedings of the National Academy of Sciences of the United States of America, 114, 6972-6977, http://dx.doi.org/doi:10.1073/pnas.1701170114.

Zhou, X. J., W. L. Li, L. X. Chen, and Y. Liu, 2006: Study on ozone change over the Tibetan Plateau. Acta Meteorologica Sinica, 20(2), 129-143. (in Chinese with English abstract) 